\section{Individuals with Disabilities Education Act}

Jacob T. Lutz ${ }^{1}$ and David E. McIntosh ${ }^{2}$

${ }^{1}$ Department of Special Education, Ball State

University, Muncie, IN, USA

${ }^{2}$ Department of Special Education, Teachers

College, Ball State University, Muncie, IN, USA

\section{Synonyms}

IDEA 2004; IDEIA; Public Law 108-446 mandates that children (ages 3-21 years) identified as having a disability in one or more of 13 specific categories shall be granted access to free, appropriate public education in the least restrictive environment possible. Title I also stipulates the provision of early intervention services to infants and toddlers (birth until 2 years) who have, or are at risk of developmental disabilities.

\section{Cross-References}

> 504 Plan

- Accommodations

\section{References and Readings}

Individuals with Disabilities Education Improvement Act of 2004, 20 U.S.C. $\S 1400$ et seq.

US Department of Education, IDEA. website: http://idea. ed.gov/. 